\title{
Impact of Gamification on User's Knowledge-Sharing Practices: Relationships between Work Motivation, Performance Expectancy and Work Engagement
}

\author{
Mario Silic \\ University of St Gallen, Switzerland \\ mario.silics@unisg.ch
}

\author{
Andrea Back \\ University of St Gallen, Switzerland \\ andrea.back@unisg.ch
}

\begin{abstract}
How to engage and motivate employees to share their knowledge has become one of the main organizational strategic goals. This study, supported by the Flow theory and Kahn's theory of engagement, investigated how the impact of gamification on user's knowledge-sharing practices. We ran an online survey of 147 participants from a large organization that implemented social engagement and motivational systems to leverage internal knowledgesharing practices. Our study revealed important drivers of job motivation (enjoyment, reciprocal benefit and recognition), which led to higher degree of job engagement and performance expectancy. From this study we derive important insights for practice and theory.
\end{abstract}

\section{Introduction}

Engaged employees represent the company's number one competitive advantage [6] impacting productivity, absenteeism, profitability, quality, customer satisfaction and, ultimately, the company's sales performance [24]. The study of U.S. workplace engagement conducted by Gallup [25], since 2000, is consistent in its findings that less than one-third of Americans are employed in organizations in which a majority of employees are indifferent regarding their or the organization's performance. How to engage and motivate employees to share their knowledge has become one of the main organizational strategic goals in which clear vision, management support and manager engagement are the key employee engagement driving factors [25]. Gamification, the use of game elements in non-game contexts [18, 39], is a recent phenomenon that has received considerable attention both from scholars and mass media. Rooted in the Flow theory, which posits that a person performing an activity (e.g., playing a game) will reach a feeling of complete and energized focus with a high level of enjoyment and fulfillment [11]. Gamification aims to reach the Flow in which an individual's mental state is focused motivation. This corresponds to an employee's commitment, concentration, focus, satisfaction, etc.- elements that affect an employee's motivation. As flow is one of the key reasons why people play games [47], it is expected that gamification will have a positive influence on employee behaviors, leading to higher motivation and engagement.

However, although scholars have made some initial steps in understanding the effects of gamification on the workplace [e.g. 3, 21, 27, 46], little theory or empirical observation accounts for the role of gamification on knowledge-sharing practices related to job engagement and motivation. In particular, researchers have not examined how and to what extent the inclusion of game design elements influences an employee's behavior towards job motivation, leading to a higher degree of job engagement and performance that impact knowledge sharing practices. This knowledge gap can be understandable, given that the gamification concept has only recently found its application in organizations and the fact that gamification is not a one-time snapshot of an employee's mental state but, instead, has to be studied over longer periods. This is where the majority of past studies failed in combination with relatively small sample sizes [33]. Clearly, there is a lack of empirical research to demonstrate that gamification leads to better results [9]. More precisely, it is unclear if gamification can influence personal (i.e., employee) engagement when employees need to be motivated to share their knowledge inside of the organizational boundaries.

Kahn [40] suggests that personal engagement is a state in which employees "bring in" their personal selves during the work role performances as they invest time and energy by experiencing a state of emotional connection with their job. This implies that work engagement is essentially a motivational 
concept that combines active allocation of personal resources toward the tasks with the work role [50]. Gamification targets the personal engagement through the state of Flow by gamifying the tasks or activities that the employee has to accomplish.

Accordingly, the purpose of this work is to draw from Theory of Flow [11] and Kahn's theory of engagement [40] to develop a theory that places gamification antecedents as key drivers of an employee's engagement and explains relationships between work motivation, performance expectancy and work engagement in the context of knowledgesharing inside of the organization.

\section{Theoretical Background}

\subsection{Theory of Flow and Gamification}

Flow theory suggested by Davis and Csikszentmihalyi [16] explains the experiences of intrinsically motivated people who are engaged in an activity chosen for its own sake. Csikszentmihalyi describes Flow as "being completely involved in an activity for its own sake. The ego falls away. Time flies. Every action, movement and thought follows inevitably from the previous one, like playing jazz. Your whole being is involved, and you're using your skills to the utmost" [63]. The Flow experience can be seen in various daily activities, such as dancing, sports, performing surgery or playing music. For example, in leisure activities such as mountain climbing, the person does not climb to reach the peak; instead, he/she attempts the peak in order to climb, meaning that the person is doing the activity for its own sake.

Games and Flow are clearly dependent [11, 44, 49] as games provide the necessary feedback with clear goals to players as pre-conditions to experience Flow [20]. In addition, games have the adaptability features as they can add or modify levels, offering challenges to players to bring the necessary balance between skills and challenges [7]. According to [10], the key to the Flow experience is to maintain the right balance between the increase of one's skills that relate to training and the increase of the task's challenges that relate to novelty. Gamification, rooted in the Flow theory, is a relatively new phenomenon that has received high attention, both from scholars and mass media.

However, today, gamification has a much broader area of application. This is also supported by the Flow theory, which posits that Flow can be reached in any area, meaning it can be applied in any product or service.
In this work, we define gamification as the application of game design elements (e.g., challenge, levels, points, leaderboards) to organizational context with the ultimate goal to influence an employee's work engagement through job satisfaction and motivation. Ultimately, users' behaviors should be impacted by the gamified tasks, in which reaching the Flow experience is the objective. This objective can be reached either through intrinsic or extrinsic motivation [52]. The intrinsic motivation can be found in the task itself, whereas extrinsic motivation comes from different external factors (e.g., financial rewards). While having extrinsic motives can produce negative outcomes [43] long term, which may impact the state of Flow, it can still be possible to activate Flow by including extrinsic incentives [52].

This is where gamification comes into play by providing incentives such as badges, that have the intrinsic component (e.g. collecting badges), but also the extrinsic dimension (e.g., gaining social recognition). In their literature review, Bui, Veit and Webster [8] divided gamification into six main categories: mechanics, technologies, individual characteristics, dynamics, outcomes and aesthetics, which have several sub-categories (e.g., Feedback, Representation, Game advancement, Rewards, Sensory, etc.). The study highlighted two interesting facts: 1) the majority of reviewed articles did not explain the technological elements of their gamified systems, and 2) only a few studies examined individual characteristics (e.g., gender, age, experience). They concluded that there is a "large gap in research of potential relevance to organizations...more research is needed on employees interacting with group systems resulting in collaboration dynamics and longer-term behavioral outcomes" [8]. This supports our argument that gamification needs to be applied over a certain time period in order to produce some meaningful and consistent impact on users' behavior.

\subsection{Kahn's Theory of Engagement}

Engagement is "the simultaneous employment and expression of a person's 'preferred self' in task behaviors that promote connections to work and to others, personal presence (physical, cognitive and emotional) and active, full performances" [40]. Accordingly, an engaged employee would be labelled as psychologically present, fully there, attentive, feeling, connected, integrated and focused in their role performances [50]. Kahn noted that employees in such situations are not only open to themselves and others, but are also connected to work and others, as 
they bring their complete selves to perform [40]. Kahn's engagement concept is all about the motivation, as it involves bringing personal resources to the performance, and also how intensely and persistently these resources are applied [41]. Kahn suggests that engagement consists of different psychological dimensions, such as effort, involvement, flow, mindfulness and intrinsic motivation. Overall, engagement in gamification corresponds to high levels of autonomous motivation that is achieved through vigor, dedication and absorption [55], in which an individual will reach a state of full absorption leading to the state of Flow, characterized by focused attention, clear mind, mind and body unison, effortless concentration, complete control, loss of self-consciousness, distortion of time and intrinsic enjoyment [11].

While engagement in the working contexts has received considerable focus from researchers [e.g. 5, $34,40,53,55]$, it is still relatively unknown how gamification can impact work engagement and employee motivation [30].

\subsection{Gamification of Knowledge Sharing}

Applications such as Stack Overflow portal or Yahoo Answers have already incorporated some game design elements to motivate users to promote knowledge sharing through a practice called Social Question and Answer. However, little is known about the organizational knowledge management-sharing practices and how gamification can leverage such activities [54]. Interestingly, past literature on knowledge management agrees that the main motivators for knowledge sharing, among several others, are: 1) recognition of job performed [35] and 2) reciprocity [4]. Added to these two is the fun, or enjoyment dimension, which is one of the important components of Flow theory [11].

According to Schacht and Maedche [54], the issue of existing knowledge-management systems is that they are "no fun... do not create an enjoyable user experience or high user satisfaction...[because] engagement and motivation...[are missing]..and they seem to be key success factors". We believe that gamification systems can alleviate these challenges by providing enjoyment, reciprocal benefit andmotivational drivers that can be provided through the use of the game design elements. Indeed, motivational aspect seems to be an important one as it supports user's willingness to search, apply and share knowledge [1]. However, an efficient gamified system that supports knowledge sharing needs to be carefully designed by using appropriate gamification elements.
Overall, we argue that an individual will be more motivated and engaged when some reciprocal benefit is experienced and when there is an element of fun or enjoyment present during the interaction process. In addition, being recognized should lead to being more motivated and, consequently, more engaged.

In the next section, we detail our hypotheses.

\subsection{Hypotheses}

Perceived reciprocal benefit is a form of social usefulness of the service, in which the user will contribute but also receive some benefits from the community [48]. According to Hamari and Koivisto [31], "The reciprocity, receiving and contributing in a manner considered beneficial by the community, is likely to be of fundamental importance in encouraging users to carry out activities encouraged by the gamification system.". The encouragement effect is clearly related to motivation, which suggests that users will continue using the system if they find the reciprocal benefit link to be beneficial for them. Consequently, we argue that if the gamified system provides clear benefits to employees, then it can be expected that employees will be more motivated to share their knowledge. Hence, we hypothesize:

H1: Perceived reciprocal benefit is correlated positively and significantly with work motivation in the context of knowledge sharing.

For Flynn [22], rewards and recognition programs keep employees' spirits high, positively impacting their performance and motivation. Clearly, if an employee receives recognition, his/her motivation will increase. Ali and Ahmed [2] study confirmed this by finding a statistically significant relationship between recognition and motivation. Hence, we hypothesize:

H2: Perceived recognition is correlated positively and significantly with work motivation in the context of knowledge sharing.

Past research has already demonstrated that playing games improves intrinsic motivation and promotes a state of heightened enjoyment $[19,52]$.

Perceived enjoyment is defined as the extent to which the activity of using the technology is "perceived to be enjoyable in its own right, apart from any performance consequences that may be anticipated" [60]. When employees enjoy the activity, they will find the interaction intrinsically interesting, meaning that they are involved in the activity for fun, pleasure and enjoyment [45]. Davis, Bagozzi and Warshaw [15] found perceived enjoyment to be an intrinsic source of motivation. We argue that when an employee experiences enjoyment, 
he or she will have higher job motivation. Hence, we hypothesize:

H3: Perceived enjoyment is correlated positively and significantly with work motivation in the context of knowledge sharing.

Performance expectancy is defined as "the degree to which an individual believes that using the system will help him/her to attain gains in job performance" [62]. In the gamification system, it can be expected that if an individual sees that system use brings him/her clear advantages (e.g., productivity increase) in relation to job tasks, then the individual's job motivation will be positively impacted. For example, if an employee receives a recognition, that will lead to a higher job motivation, which ultimately will affect the employee's performance expectancy, in which it can be expected that the employee's job performance will improve. In other words, if, for example, an employee is rewarded by his manager, this would impact the job motivation and, consequently, his/her performance expectancy. Hence, we hypothesize:

H4: Job motivation is correlated positively and significantly with performance expectancy in the context of knowledge sharing.

Prior empirical findings showed that employees with high intrinsic motivation are spending more time on organizational tasks, have more positive moods and experience less anxiety in the workplace [17]. Therefore, if employees feel motivated, they will be more engaged with their work. Similarly, if the gamification system brings performance-related benefits to employees, then we can expect that an employee will be more engaged with his/her work. For example, since knowledge-sharing practices will be increased as a consequence of using the gamification system, we argue that work engagement will be higher as result of increased performance expectancy. Hence, we hypothesize:

H5: Job motivation is correlated positively and significantly with work engagement in the context of knowledge sharing.

H6: Performance expectancy is correlated positively and significantly with work engagement in the context of knowledge sharing.

\section{Research Methodology}

\subsection{Research Setting and Participants}

To test our research model, we collected data from employees from a large international company that implemented an internal social engagement and motivation platform (bravo system) that enables each employee to recognize another employee for a certain task related to knowledge sharing. The entire system is fully gamified and uses different gamification elements (leaderboards, points, scoring, levels, challenges to solve, incentives, employee picture, team rewards and badges). The system works as follows. An employee can reward another employee or a group of employees by giving a certain amount of points that are accumulated by each employee. The number of points determine the employee's level and associated badges. Points can be spent either on travel or to purchase different goods through an external website. Along with awarding points, employees can also just say "bravo" to another employee. All bravo recognitions are related to some specific knowledge- sharing practices that employees demonstrate.

Two groups of participants were contacted: 1) employees who were already active users on the Bravo system and 2) employees who never used the system (non-bravo users) who acted as our control group. All contacted employees were involved in the knowledge-sharing processes. That is, they were all involved in a certain type of product or project management process in which sharing knowledge is one of the important processes.

\subsection{Procedures and Measurement}

Data was collected from both types of users (bravo users and the control group) using an online questionnaire. In addition, since we did not want to rely on one-time data collection, we decided to have a longitudinal approach. That is, we collected the data over a six month-period collecting data at regular intervals. The purpose of doing this was to avoid the short gamification effect from which many past studies suffered. Indeed, gamification is a process that takes time and needs to be run over a longer period to see any effects on users' behaviors.

Measurement items are presented in Appendix II.

\section{Results}

Now, we present our detailed findings. First, we detail the participants' demographics. Second, we explore the measurement model results and finish with assessing our initial hypotheses.

\subsection{Demographics}

In total, we had 175 participants that completed the survey. We removed 28 for implausible answers 
(time less than two minutes) or incomplete/missing information. The final sample accounted for 147 participants (95 were men and 52 women). Demographics were represented as follows: U.S. 61, France 24, U.K. 15, Spain 11, India 10, Turkey 8, Poland 5, Croatia 5, UAE 5 and Russia 3.

\subsection{Model Testing, Validity and Reliability}

We use partial least squares (PLS) to test our theoretical model using SmartPLS [51]. The PLS method has a wide acceptance and use in IS security studies [37, 56, 57]. We opted for a structural equation modelling (SEM) technique rather than regression as we aimed for testing measurement and a structural model. Also, PLS proved to be useful in the exploratory theory-building process [57].

The composite reliabilities of the different measures range from 0.92 to 0.97 , which exceeds the recommended threshold value of 0.70 . Also, as per Fornell and Larcker [23], the recommended average variance extracted (AVE) for each variable construct exceeds 0.50 , ranging from 0.70 to 0.87 .

According to the Fornell-Larcker criterion [23], the AVE of each latent construct should be higher than the construct's highest squared correlation with any other latent construct. We conclude that the discriminant validity (Table 1) test has been established. Also, factor Loadings (boldface) and cross Loadings were calculated (Appendix I - Table 1).

Further, Stone-Geisser Q-squared coefficients were calculated for each of the endogenous variables in the study's path model [26, 58]. Each of the endogenous variables in the study's model exhibited Q-squared coefficients greater than zero, thereby presenting acceptable predictive validity. Finally, a full collinearity check that was based on the variance inflation factors (VIFs) for each of the latent variables was conducted. The recommended VIF value should be lower than 5 [29], and, taking into account that the highest VIF score is 4.45 , we concluded that no existence of multicollinearity can be supported.

We repeated the same procedure for the control group model and obtained same conclusions. That is, we concluded that discriminant validity and reliability are acceptable. Finally, we controlled for the common method bias and found that it is not a concern for this research.

\subsection{Structural Model}

To assess our hypotheses, we examined the parameters provided by the PSL structural model. Our structural model results (Figure 1) indicate that all of our hypotheses are supported.

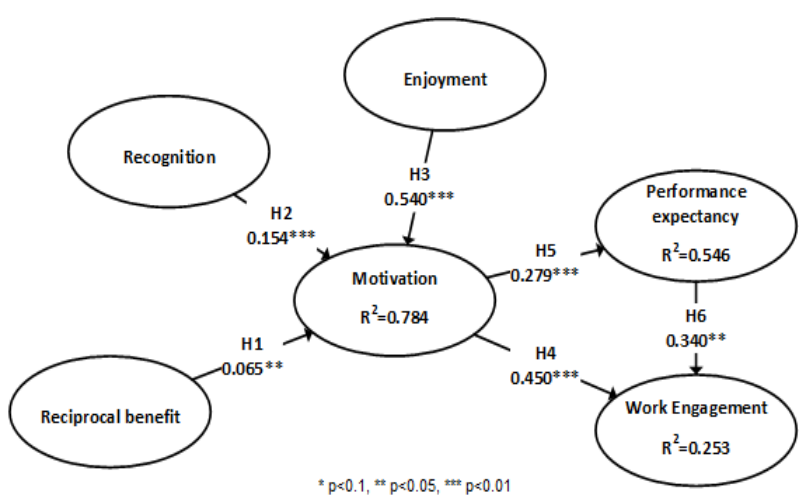

Figure 1. Structural model results

\begin{tabular}{|c|c|c|c|c|c|c|}
\hline & $\begin{array}{l}\text { ENJ } \\
\text { OY }\end{array}$ & $\begin{array}{l}\text { MOT } \\
\text { IV }\end{array}$ & $\begin{array}{l}\text { PER } \\
\text { EX }\end{array}$ & $\begin{array}{l}\text { REC } \\
\text { BE }\end{array}$ & $\begin{array}{l}\text { REC } \\
\mathrm{O}\end{array}$ & WE \\
\hline ENJOY & 0.9 & & & & & \\
\hline MOTIV & 0.84 & 1 & & & & \\
\hline PEREX & 0.59 & 0.73 & 0.93 & & & \\
\hline RECBE & 0.69 & 0.73 & 0.68 & 0.93 & & \\
\hline RECO & 0.63 & 0.70 & 0.59 & 0.68 & 0.89 & \\
\hline WE & 0.37 & 0.44 & 0.48 & 0.48 & 0.17 & 0.83 \\
\hline
\end{tabular}

\subsection{Control Group Results}

Control group results were obtained using the same questionnaire that was used with the gamification group but with some modifications: 1) instead of asking about the bravo system, employees were asked about current knowledge- sharing practice process, and 2) several item questions were slightly adapted to match the new wording, but without any logic or sense change. Results showed that $\mathrm{H} 1$ is supported $(\beta=0.177, \mathrm{p}<0.01), \mathrm{H} 2(\beta=$ $0.154, \mathrm{NS}), \mathrm{H} 3$ ( $\beta=0.101, \mathrm{NS}), \mathrm{H} 4(\beta=0.212$, NS), H5 $(\beta=0.222, \mathrm{NS})$ and H6 $(\beta=0.094$, NS). We have also performed partial least squares multi-group analysis (PLS-MGA) following the method as suggested by [36]. After analyzing the bootstrap outputs, we concluded that the gamification system is positively impacting employees' behaviors when compared to the control group, in which this impact is not present.

\section{Discussion}


This study sought to understand the impact of gamification on user's knowledge-sharing practices through gamified social engagement and motivational System.

\subsection{Theoretical Contributions}

There are several theoretical contributions offered in this study. First, we identified key antecedents to job motivation, theorizing that reciprocal benefit, recognition and enjoyment lead to higher job motivation. This confirms our initial hypothesis that gamification would lead to higher job motivation. More precisely, in the context of knowledge-sharing practices, it seems that employees are more motivated to share their knowledge when it could benefit them. Also, being recognized for their knowledge-sharing behaviors and, at the same time, having fun and enjoying, influences employees' motivation. Indeed, KM literature highlights the importance of motivation [13] where providing incentives clearly impacts knowledge sharing.

Second, we found a strong relationship between motivation and performance expectancy and job engagement. This is an important finding as it suggests that the inclusion of game design elements influences employees behaviors toward job engagement and also its performance expectancy. A study done by Danish and Usman [12] revealed that incentives, reward and recognition do have a great impact on employee motivation. In our context, knowledge-sharing practices seem to be positively impacted by the motivational dimension in which employees tend to be more engaged with their job as a consequence of different motivation drivers. Interestingly, social Q\&A sites are already using gamification to increase the knowledge sharing practices of their participants [61]. Third, we found that performance expectancy directly and positively influences job engagement in the context of knowledge sharing. This suggests that a motivated employee, that is recognized, enjoys the activity, has fun, derives a benefit from using the system and will perform better as result of increased knowledgesharing practices. This will ultimately affect work engagement. Also, when employees are incentivized to collaborate with others, they tend to increase their knowledge sharing practices [59].

Overall, our study offers new insights about employee work engagement and the impact of gamification elements relying on Theory of Flow [11] and Kahn's theory of engagement [40].

\subsection{Practitioner Contributions}

We also offer some practical contributions. Our study suggests that implementing a gamification system could leverage an employee's knowledgesharing practices in the organizational context. That is, employees see a benefit in the gamification system use as they are recognized by their peers or managers. Another point that could be interesting in the organizational context relates to motivational dimension. Overall, employees' motivation to share their knowledge is one of the challenges for organizations. Approaching this topic through game design elements seems to influence employees' behavior in a positive way. Hence, organizations could leverage the use of the gamification system to customize it more to their knowledge-sharing practices needs. Ultimately, this would lead not only to an increase in performance expectancy but also to an increase in job engagement.

\subsection{Limitations and Future Research}

Our study is limited by the fact that we ran it in a single organization. It would be interesting to involve more organizations to see what other factors (e.g., organizational culture) could impact the overall results. Further, although we did have a control group of employees who never used the gamification system in place, some of these employees could have heard about the gamification system, which could consequently have some influence on the results of the control group. Another limitation is the fact that we did not really measure any knowledge-sharing practice. Finally, although our study is longitudinal in design, six months period may not be an ideal timeframe for measuring gamification effects.

We suggest further research that will explore how job satisfaction is influenced by different motivation drivers and, ultimately, investigate the relationship between job satisfaction and work engagement. Another interesting direction for future studies is to understand the role of different game design elements: how and to what extent these elements influence (in a positive or negative way) long-term work engagement, motivation and job satisfaction.

\section{References}

[1] Alavi, M., and Leidner, D.E., "Review: Knowledge Management and Knowledge Management Systems: Conceptual Foundations and Research Issues", MIS quarterly, 25(1), 2001, pp. 107.

[2] Ali, R., and Ahmed, M.S., "The Impact of Reward and Recognition Programs on Employee's Motivation and 
Satisfaction: An Empirical Study", International review of business research papers, 5(4), 2009, pp. 270-279.

[3] Anderson, A., Huttenlocher, D., Kleinberg, J., and Leskovec, J., "Steering User Behavior with Badges", in (Editor, 'ed.'^'eds.'): Book Steering User Behavior with Badges, International World Wide Web Conferences Steering Committee, 2013, pp. 95-106.

[4] Ardichvili, A., Page, V., and Wentling, T., "Motivation and Barriers to Participation in Virtual Knowledge-Sharing Communities of Practice", Journal of knowledge management, 7(1), 2003, pp. 64-77.

[5] Bakker, A.B., and Demerouti, E., "Towards a Model of Work Engagement", Career development international, 13(3), 2008, pp. 209-223.

[6] Boyce, C. (2015). Engaged Employees: Your Company's No. 1 Competitive Advantage Retrieved February 2016, from http://www.huffingtonpost.com/chrisboyce/engaged-employees-your-co b 6344230.html

[7] Bressler, D., and Bodzin, A., "A Mixed Methods Assessment of Students' Flow Experiences During a Mobile Augmented Reality Science Game", Journal of Computer Assisted Learning, 29(6), 2013, pp. 505-517.

[8] Bui, A., Veit, D., and Webster, J., "Gamification-a Novel Phenomenon or a New Wrapping for Existing Concepts?", International Conference on Information Systems, 2015

[9] Cechanowicz, J., Gutwin, C., Brownell, B., and Goodfellow, L., "Effects of Gamification on Participation and Data Quality in a Real-World Market Research Domain", in (Editor, 'ed.'^'eds.'): Book Effects of Gamification on Participation and Data Quality in a RealWorld Market Research Domain, ACM, 2013, pp. 58-65.

[10] Cowley, B., Charles, D., Black, M., and Hickey, R., "Toward an Understanding of Flow in Video Games", Computers in Entertainment (CIE), 6(2), 2008, pp. 20.

[11] Csikszentmihalyi, M., Beyond Boredom and Anxiety, Jossey-Bass, San Francisco, CA, US, 2000.

[12] Danish, R.Q., and Usman, A., "Impact of Reward and Recognition on Job Satisfaction and Motivation: An Empirical Study from Pakistan", International journal of business and management, 5(2), 2010, pp. 159.

[13] Davidson, E., and Lamb, R., "Examining SocioTechnical Networks in Scientific Academia/Industry Collaborations", AMCIS 2000 Proceedings, 2000, pp. 202.

[14] Davis, F.D., "Perceived Usefulness, Perceived Ease of Use, and User Acceptance of Information Technology", MIS quarterly, 13(3), 1989, pp. 319.
[15] Davis, F.D., Bagozzi, R.P., and Warshaw, P.R., "Extrinsic and Intrinsic Motivation to Use Computers in the Workplace1", Journal of applied social psychology, 22(14), 1992, pp. 1111-1132.

[16] Davis, M., and Csikszentmihalyi, M., Beyond Boredom and Anxiety: The Experience of Play in Work and Games, Amer Sociological Assoc, Washington, DC, 1977.

[17] Deci, E.L., and Ryan, R.M., Intrinsic Motivation, Wiley Online Library, 1975.

[18] Deterding, S., Dixon, D., Khaled, R., and Nacke, L., "From Game Design Elements to Gamefulness: Defining Gamification", in (Editor, 'ed.'^'eds.'): Book From Game Design Elements to Gamefulness: Defining Gamification, ACM, 2011, pp. 9-15.

[19] Epstein, J.A., and Harackiewicz, J.M., "Winning Is Not Enough: The Effects of Competition and Achievement Orientation on Intrinsic Interest", Personality and Social Psychology Bulletin, 18(2), 1992, pp. 128-138.

[20] Fang, X., Zhang, J., and Chan, S.S., "Development of an Instrument for Studying Flow in Computer Game Play", International journal of human-computer interaction, 29(7), 2013, pp. 456-470.

[21] Flatla, D.R., Gutwin, C., Nacke, L.E., Bateman, S., and Mandryk, R.L., "Calibration Games: Making Calibration Tasks Enjoyable by Adding Motivating Game Elements", in (Editor, 'ed.'^'eds.'): Book Calibration Games: Making Calibration Tasks Enjoyable by Adding Motivating Game Elements, ACM, 2011, pp. 403-412.

[22] Flynn, G., "Is Your Recognition Program Understood", Workforce, 77(7), 1998, pp. 30-35.

[23] Fornell, C., and Larcker, D.F., "Evaluating Structural Equation Models with Unobservable Variables and Measurement Error", Journal of marketing Research, 18(1), 1981, pp. 39.

[24] Gallup. (2013). How Employee Engagement Drives Growth Retrieved February 2016, from http://www.gallup.com/businessjournal/163130/employeeengagement-drives-growth.aspx

[25] Gallup. (2015). State of the American Manager Retrieved February 2016, from http://www.gallup.com/services/182138/state-americanmanager.aspx

[26] Geisser, S., "A Predictive Approach to the Random Effect Model", Biometrika, 61(1), 1974, pp. 101-107.

[27] Grant, S., and Betts, B., "Encouraging User Behaviour with Achievements: An Empirical Study", in (Editor, 
'ed.'^'eds.'): Book Encouraging User Behaviour with Achievements: An Empirical Study, IEEE, 2013, pp. 65-68.

[28] Guay, F., Vallerand, R.J., and Blanchard, C., "On the Assessment of Situational Intrinsic and Extrinsic Motivation: The Situational Motivation Scale (Sims)", Motivation and emotion, 24(3), 2000, pp. 175-213.

[29] Hair, J.F., Multivariate Data Analysis, Prentice Hall, Upper Saddle River, 2009.

[30] Hamari, J., "Transforming Homo Economicus into Homo Ludens: A Field Experiment on Gamification in a Utilitarian Peer-to-Peer Trading Service", Electronic commerce research and applications, 12(4), 2013, pp. 236245.

[31] Hamari, J., and Koivisto, J., "Social Motivations to Use Gamification: An Empirical Study of Gamifying Exercise", in (Editor, 'ed.'^'eds.'): Book Social Motivations to Use Gamification: An Empirical Study of Gamifying Exercise, 2013, pp. 105.

[32] Hamari, J., and Koivisto, J., "“Working out for Likes": An Empirical Study on Social Influence in Exercise Gamification", Computers in Human Behavior, 50(2015, pp. 333-347.

[33] Hamari, J., Koivisto, J., and Sarsa, H., "Does Gamification Work?--a Literature Review of Empirical Studies on Gamification", in (Editor, 'ed.'^'eds.'): Book Does Gamification Work?--a Literature Review of Empirical Studies on Gamification, IEEE, 2014, pp. 30253034.

[34] Harter, J.K., Schmidt, F.L., and Hayes, T.L., "Business-Unit-Level Relationship between Employee Satisfaction, Employee Engagement, and Business Outcomes: A Meta-Analysis", Journal of applied psychology, 87(2), 2002, pp. 268.

[35] Hendriks, P., "Why Share Knowledge? The Influence of Ict on the Motivation for Knowledge Sharing", Knowledge and process management, 6(2), 1999, pp. 91.

[36] Henseler, J., Ringle, C.M., and Sinkovics, R.R., "The Use of Partial Least Squares Path Modeling in International Marketing", Advances in international marketing, 20(1), 2009, pp. 277-319.

[37] Herath, T., and Rao, H.R., "Encouraging Information Security Behaviors in Organizations: Role of Penalties, Pressures and Perceived Effectiveness", Decision Support Systems, 47(2), 2009, pp. 154-165.

[38] Hsu, C.-L., and Lin, J.C.-C., "Acceptance of Blog Usage: The Roles of Technology Acceptance, Social Influence and Knowledge Sharing Motivation", Information \& Management, 45(1), 2008, pp. 65-74.
[39] Huotari, K., and Hamari, J., "A Definition for Gamification: Anchoring Gamification in the Service Marketing Literature", Electronic Markets, 2016, pp. 1-11.

[40] Kahn, W.A., "Psychological Conditions of Personal Engagement and Disengagement at Work", Academy of management journal, 33(4), 1990, pp. 692-724.

[41] Kanfer, R., "Motivation Theory and Industrial and Organizational Psychology", Handbook of industrial and organizational psychology, 1(2), 1990, pp. 75-130.

[42] Lin, H.-F., "Determinants of Successful Virtual Communities: Contributions from System Characteristics and Social Factors", Information \& Management, 45(8), 2008, pp. 522-527.

[43] Mcgonigal, J., Reality Is Broken: Why Games Make Us Better and How They Can Change the World, Penguin, New York, US, 2011.

[44] Mitchell Jr, R.G., "Sociological Implications of the Flow Experience", Cambridge University Press, New York, 1988, pp. 36-59.

[45] Moon, J.-W., and Kim, Y.-G., "Extending the Tam for a World-Wide-Web Context", Information \& Management, 38(4), 2001, pp. 217-230.

[46] Morschheuser, B., Henzi, C., and Alt, R., "Increasing Intranet Usage through Gamification--Insights from an Experiment in the Banking Industry", in (Editor, 'ed.'^'eds.'): Book Increasing Intranet Usage through Gamification--Insights from an Experiment in the Banking Industry, IEEE, 2015, pp. 635-642.

[47] Murphy, C., "Why Games Work and the Science of Learning", in (Editor, 'ed.'^'eds.'): Book Why Games Work and the Science of Learning, Citeseer, 2011, pp. 260-272.

[48] Preece, J., "Sociability and Usability in Online Communities: Determining and Measuring Success", Behaviour \& Information Technology, 20(5), 2001, pp. 347-356.

[49] Rathunde, K., "Optimal Experience and the Family Context": Optimal Experience: Psychological Studies of Flow in Consciousness. , Cambridge University Press, 1988, pp. 342-363.

[50] Rich, B.L., Lepine, J.A., and Crawford, E.R., "Job Engagement: Antecedents and Effects on Job Performance", Academy of management journal, 53(3), 2010, pp. 617-635.

[51] Ringle, C., Wende, S., and Will, A., "Smart Pls 2.0 M3, University of Hamburg", in (Editor, 'ed.'^'eds.'): Book Smart Pls 2.0 M3, University of Hamburg, 2005 
[52] Ryan, R.M., and Deci, E.L., "Self-Determination Theory and the Facilitation of Intrinsic Motivation, Social Development, and Well-Being", American psychologist, 55(1), 2000, pp. 68.

[53] Saks, A.M., "Antecedents and Consequences of Employee Engagement", Journal of managerial psychology, 21(7), 2006, pp. 600-619.

[54] Schacht, S., and Maedche, A., "Project Knowledge Management While Simply Playing! Gaming Mechanics in Project Knowledge Management Systems": Gamification in Education and Business, Springer, 2015, pp. 593-614.

[55] Schaufeli, W.B., Salanova, M., González-Romá, V., and Bakker, A.B., "The Measurement of Engagement and Burnout: A Two Sample Confirmatory Factor Analytic Approach", Journal of Happiness studies, 3(1), 2002, pp. 71-92.

[56] Siponen, M., and Vance, A., "Neutralization: New Insights into the Problem of Employee Systems Security Policy Violations", MIS quarterly, 34(3), 2010, pp. 487502.

[57] Siponen, M., Vance, A., and Willison, R., "New Insights into the Problem of Software Piracy: The Effects of Neutralization, Shame, and Moral Beliefs", Information \& Management, 49(7), 2012, pp. 334-341.

[58] Stone, M., "Cross-Validatory Choice and Assessment of Statistical Predictions", Journal of the Royal Statistical Society. Series B (Methodological), 1974, pp. 111-147.

[59] Van Alstyne, M., and Brynjolfsson, E., "Electronic Communities: Global Village or Cyberbalkans?", in (Editor, 'ed.'^'eds.'): Book Electronic Communities: Global Village or Cyberbalkans?, 1996

[60] Van Der Heijden, H., "Factors Influencing the Usage of Websites: The Case of a Generic Portal in the Netherlands", Information \& management, 40(6), 2003, pp. 541-549.

[61] Vasilescu, B., Serebrenik, A., Devanbu, P., and Filkov, V., "How Social Q\&a Sites Are Changing Knowledge Sharing in Open Source Software Communities", in (Editor, 'ed.'^'eds.'): Book How Social Q\&a Sites Are Changing Knowledge Sharing in Open Source Software Communities, ACM, 2014, pp. 342-354.

\section{APPENDIX II: Questionnaire Items}

Enjoyment - Adapted from [14]

EN1: I find the experience of BRAVO system use enjoyable

EN2:I find the experience of BRAVO system use pleasant EN3:I find the experience of BRAVO system use exciting
[62] Venkatesh, V., Morris, M.G., Davis, G.B., and Davis, F.D., "User Acceptance of Information Technology:

Toward a Unified View", MIS quarterly, 2003, pp. 425478.

[63] Wired. (1996). Go with the Flow Retrieved February 2016, from http://www.wired.com/1996/09/czik/

\section{APPENDIX I - Validity Tests}

\begin{tabular}{|c|c|c|c|c|c|c|}
\hline & $\begin{array}{l}\text { ENJ } \\
\text { OY }\end{array}$ & $\begin{array}{l}\text { MOT } \\
\text { IV }\end{array}$ & PEREX & $\begin{array}{l}\text { REC } \\
\text { BE }\end{array}$ & $\begin{array}{l}\text { REC } \\
\text { O }\end{array}$ & WE \\
\hline EN1 & $\mathbf{0 . 8 7}$ & 0.82 & 0.60 & 0.75 & 0.74 & 0.39 \\
\hline EN2 & $\mathbf{0 . 9 1}$ & 0.76 & 0.45 & 0.48 & 0.53 & 0.32 \\
\hline EN3 & $\mathbf{0 . 9 2}$ & 0.76 & 0.55 & 0.62 & 0.54 & 0.22 \\
\hline EN4 & $\mathbf{0 . 8 9}$ & 0.71 & 0.54 & 0.65 & 0.44 & 0.43 \\
\hline $\begin{array}{c}\text { MOT } \\
\text { IV }\end{array}$ & 0.85 & $\mathbf{1 . 0 0}$ & 0.74 & 0.74 & 0.71 & 0.45 \\
\hline PE1 & 0.54 & 0.66 & $\mathbf{0 . 9 4}$ & 0.54 & 0.51 & 0.42 \\
\hline PE2 & 0.53 & 0.64 & $\mathbf{0 . 9 1}$ & 0.65 & 0.66 & 0.41 \\
\hline PE3 & 0.60 & 0.72 & $\mathbf{0 . 9 5}$ & 0.70 & 0.49 & 0.55 \\
\hline PE4 & 0.53 & 0.68 & $\mathbf{0 . 9 2}$ & 0.62 & 0.65 & 0.31 \\
\hline PE5 & 0.57 & 0.73 & $\mathbf{0 . 9 3}$ & 0.66 & 0.50 & 0.54 \\
\hline RB1 & 0.67 & 0.69 & 0.65 & $\mathbf{0 . 9 7}$ & 0.65 & 0.48 \\
\hline RB2 & 0.65 & 0.61 & 0.56 & $\mathbf{0 . 9 4}$ & 0.52 & 0.38 \\
\hline RB3 & 0.69 & 0.69 & 0.61 & $\mathbf{0 . 9 5}$ & 0.61 & 0.38 \\
\hline RB4 & 0.59 & 0.75 & 0.71 & $\mathbf{0 . 8 9}$ & 0.75 & 0.57 \\
\hline $\begin{array}{c}\text { REC } \\
1\end{array}$ & 0.67 & 0.67 & 0.48 & 0.52 & $\mathbf{0 . 8 5}$ & 0.11 \\
\hline $\begin{array}{c}\text { REC } \\
2\end{array}$ & 0.51 & 0.62 & 0.59 & 0.63 & $\mathbf{0 . 9 1}$ & 0.22 \\
\hline $\begin{array}{c}\text { REC } \\
3\end{array}$ & 0.51 & 0.62 & 0.54 & 0.70 & $\mathbf{0 . 9 3}$ & 0.13 \\
\hline WE1 & 0.13 & 0.24 & 0.25 & 0.07 & 0.00 & $\mathbf{0 . 7 7}$ \\
\hline WE2 & 0.19 & 0.32 & 0.41 & 0.26 & 0.16 & $\mathbf{0 . 8 0}$ \\
\hline WE5 & 0.33 & 0.39 & 0.41 & 0.39 & 0.25 & $\mathbf{0 . 9 0}$ \\
\hline WE6 & 0.40 & 0.43 & 0.41 & 0.39 & 0.18 & $\mathbf{0 . 7 9}$ \\
\hline WE7 & 0.30 & 0.35 & 0.42 & 0.51 & 0.01 & $\mathbf{0 . 8 6}$ \\
\hline WE8 & 0.43 & 0.47 & 0.49 & 0.66 & 0.20 & $\mathbf{0 . 9 1}$ \\
\hline
\end{tabular}

Table 1. Factor Loadings (boldface) and Cross Loadings

EN4:I find the experience of BRAVO system use interesting

Recognition - Adapted from [32]

REC1: I feel good when my achievements in BRAVO system are noticed 
REC2:I like it when other BRAVO users comment and award my achievements

REC3:I like it when my peers notice my BRAVO recognitions

Reciprocal benefit - Adapted from [38, 42, 48]

RB1: I find that participating in the BRAVO system can be mutually helpful

RB2: I find that my participation in the BRAVO system can be advantageous to me and other people

RB3: I think that participating in the BRAVO system improves my motivation to recognize others

RB4: The BRAVO system encourages me to provide recognitions for others

Work Engagement - Adapted from [50]

To which extent BRAVO system improves your work engagement:

WE1: I work with intensity on my job.

WE2: I exert my full effort to my job.

WE3: I devote a lot of energy to my job.

WE4: I try my hardest to perform well on my job.

WE5: I am interested in my job.

WE6: I am proud of my job.

WE7: I feel positive about my job.

WE8: I am excited about my job.

Performance expectancy - Adapted from [62]

Being recognized through BRAVO system

PE1: would motivate me to accomplish tasks more quickly.

PE2:would improve my job performance.

PE3: would increase my productivity.

PE4:would enhance my effectiveness on the job.

PE5:would motivate me it easier to do my job.
The Situational Motivation Scale (SIMS) Adapted from [28]

Why are you currently engaged in BRAVO activity?

MS1: Because I think that this activity is interesting MS2: Because I am doing it for my own good

MS3:Because I am supposed to do it

MS4:There may be good reasons to do this activity, but personally I don't see any

MS5: Because I think that this activity is pleasant

MS6: Because I think that this activity is good for me

MS7: Because it is something that I have to do

MS8: I do this activity but I am not sure if it is worth it

MS9: Because this activity is fun

MS10: By personal decision

MS11:. Because I don't have any choice

MS12: I don't know; I don't see what this activity brings me

MS13: Because I feel good when doing this activity

MS14:Because I believe that this activity is important for me

MS15:Because I feel that I have to do it

MS16:I do this activity, but I am not sure it is a good thing to pursue it

Codification key:

Intrinsic motivation: Items 1, 5, 9, 13; Identified regulation: Items 2, 6, 10, 14; External regulation: Items 3,7, 11, 15; Amotivation: Items 4, 8, 12, 16.

$*=$ reverse scaled;

All scales were reflective and used a Likert-like seven-point scale anchored on "Strongly Disagree" to "Strongly Agree." 